\title{
UM NOVO CAPITAL CULTURAL: PRÉ-DISPOSIÇÕES E DISPOSIÇÕES À CULTURA INFORMAL NOS SEGMENTOS COM BAIXA ESCOLARIDADE
}

\author{
Maria da Graça Jacintho Setton ${ }^{*}$
}

\begin{abstract}
RESUMO: Este estudo tem como objetivo analisar alguns aspectos das trajetórias pessoais e familiares de alunos que tiveram um sucesso acadêmico improvável. De origem popular, com baixos rendimentos e pequena herança de uma cultura escolar, os alunos pesquisados destacaram-se de um universo de estudantes que ingressaram nos cursos considerados de elite da Universidade de São Paulo. ${ }^{1}$ Para empreender esta análise irei me apoiar no conceito de capital cultural, de Pierre Bourdieu, propondo uma ampliação interpretativa deste conceito. As contribuições metodológicas de Bernard Lahire terão também um papel de destaque nesta análise. Proponho compreender as trajetórias de sucesso dos indivíduos pesquisados segundo a perspectiva utilizada por Lahire, não obstante não me restringirei apenas à idéia de configuração entre as instâncias da família e da escola, elaborada por ele. Parto da hipótese de que o estudante brasileiro contemporâneo socializa-se a partir da interdependência entre sistemas de referências híbridos, forjados com base nas instâncias tradicionais da educação, mas também por um sistema difuso de conhecimentos e informaçôes veiculados pela mídia.
\end{abstract}

Palavras-chave: Socialização. Mídia. Estudante universitário. Sucesso escolar. Capital cultural.

A NEW CULTURAL CAPITAL:

PRE-DISPOSITIONS AND DISPOSITIONS TO THE INFORMAL CULTURE IN THE SEGMENTS OF LOW EDUCATION

ABSTRACT: This study aims to analyze some aspects of personal and familiar trajectories of students who had not a probable academic success. From poorer ancestry, with low income and low in-

Professora de sociologia da Faculdade de Educação da Universidade de São Paulo (USP). E-mail: gracaset@usp.br

Educ. Soc., Campinas, vol. 26, n. 90, p. 77-105, Jan./Abr. 2005

Disponível em <http://www.cedes.unicamp.br> 
Um novo capital cultural: pré-disposições e disposições à cultura...

heritance of scholar culture, the students researched surpassed a universe of students who entered in courses considered as elite from the University of São Paulo. To undertake this analysis I will use as base Pierre Bordieu's concept of cultural capital, proposing an interpretative amplification of this concept. Bernard Lahire's methodological contribution will also have a prominent role in this analysis. I propose to understand the success course of the individuals researched according to Lahire's perspectives, although I will not limit the subject only to the aspect between the family instance and the school written by him. To my mind the Brazilian contemporary student socializes not only as of interdependence among hybrid references, shaped as of the traditional instances of the education but also through a diffuse system of knowledge and information propagated by the media.

Key words: Socialization. Media. Graduate students. Academic success. Cultural capital.

\section{Sobre as pré-disposições e disposições à cultura informal}

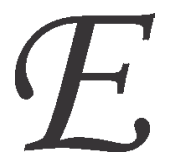

$\mathrm{m}$ Les héritiers, les étudiantes et la culture, Pierre Bourdieu \& Jean Claude Passeron (1964), em um estudo pioneiro, com base em uma abordagem macroestrutural, analisam os índices de produtividade escolar entre jovens franceses de distinta origem social. Desmistificando o discurso da escola libertadora, Bourdieu explicita os mecanismos perversos e ocultos responsáveis pelas desigualdades no aproveitamento e no rendimento de estudantes pertencentes a diferentes grupos sociais. Em outro texto, mais precisamente em Os três estados do capital cultural, este autor esclarece: "A noção de capital cultural impôs-se, primeiramente, como uma hipótese indispensável para dar conta da desigualdade de desempenho escolar de crianças provenientes das diferentes classes sociais" (Bourdieu, 1998, p. 73). Dando continuidade à suas investigaçôes, em $A$ escola conservadora: as desigualdades frente à escola e à cultura (1998), Bourdieu com base em análises estatísticas, observa também que existe uma correlação estreita entre algumas variáveis pertinentes ao perfil da família e o sucesso escolar de seus filhos. Além da formação cultural dos antepassados da primeira e segunda geraçóes e do local de residência da família (centro ou periferia), o autor chama atenção para o ramo do estudo secundário (profissionalizante ou propedêutico), o tipo de 
estabelecimento de ensino (público ou privado) do estudante, bem como para o modelo demográfico da família e o sentido da trajetória social (ascendente ou descendente) do chefe do grupo familiar, como variáveis importantes e fortemente relacionadas com o sucesso educacional dos estudantes (Bourdieu, 1998, p. 42-45).

No entanto, para ele, nenhuma dessas variáveis desempenharia isoladamente um fator determinante. O que interessava afirmar é que existem fatores extra-escolares - econômicos e culturais - que influenciam sobremaneira no desempenho e no aproveitamento do estudante. $\mathrm{O}$ importante era revelar que existem diferenças de várias ordens, principalmente de acesso aos bens da cultura, entre as famílias, que são responsáveis pela variação no comportamento e no rendimento relativos aos estudos.

Ou seja, afirmava que "na realidade, cada família transmite a seus filhos, mais por vias indiretas que diretas, um certo capital cultural e um certo ethos, sistema de valores implícitos e profundamente interiorizados, que contribui para definir, entre outras coisas, as atitudes em face do capital cultural e da instituição escolar" (Bourdieu, 1998, p. 42). Isto é, a posse de um certo capital cultural e de um ethos familiar predisposto a valorizar e incentivar o conhecimento escolar seriam importantes elementos para se alcançar um sucesso acadêmico. Neste sentido, crianças mais abastadas e com maior acesso aos bens culturais seriam aquelas que teriam as maiores chances de obter um bom desempenho escolar.

Em síntese, Bourdieu alertou para as diferenças nas condições de acesso a uma cultura geral e, como decorrência, apontou para as condiçôes diferenciadas de aquisição de uma cultura escolar. Em outras palavras, distinguiu dois tipos de aprendizado; de um lado, o aprendizado precoce e insensível, efetuado desde a primeira infância, no ambiente familiar, podendo ou não ser prolongado por um aprendizado escolar que o pressupóe e o complementa; de outro, o aprendizado tardio, metódico, adquirido fora da família, nas instituiçóes de ensino ou em outras esferas informais da educação. A distinçãao entre esses dois tipos de aprendizado refere-se, pois, a duas maneiras de adquirir a cultura e de ter acesso a ela, e com ela se familiarizar (Bourdieu, 1979, 1998). Neste sentido, para Bourdieu "capital cultural" é um conceito que explicita um novo tipo de capital, um novo recurso social, fonte de distinção e 
Um novo capital cultural: pré-disposições e disposições à cultura...

poder em sociedades em que a posse desse recurso é privilégio de poucos (Bourdieu, 1996a). Refere-se a um conjunto de estratégias, valores e disposições promovidos principalmente pela família, pela escola e pelos demais agentes da educação, que predispõe os indivíduos a uma atitude dócil e de reconhecimento ante as práticas educativas.

Para o desenvolvimento desta reflexão, seria importante alertar, no entanto, que o capital cultural como recurso estratégico pode ser cultuado de várias formas. Ou seja, é preciso salientar que a posse desse novo capital pode derivar de investimentos culturais diversos. Pode se expressar na forma de diplomas, na visitação a museus e assistência a concertos eruditos ou, na sua impossibilidade, pode se expressar em comportamentos menos aristocráticos não deixando de ser utilizado como capital distintivo. Isto é, na falta de diplomas, na ausência do hábito de freqüentar os templos da cultura, esse novo recurso pode ser explicitado em atitudes mais simples. Neste estudo quero salientar que a leitura de jornais e revistas, a assistência interessada a uma programação televisiva informativa, a audiência a entrevistas com especialistas, ou viagens pela internet (entre outras possibilidades) podem servir também como estratégias de adquirir os bens da cultura e do conhecimento e de ter acesso a estes. Em outras palavras, quero destacar uma outra ordem de estratégias e/ou práticas culturais que demonstram uma abertura ante o aprendizado informal/formal difundido por instâncias ainda não consagradas como legítimas. ${ }^{2}$

De uma certa forma o que proponho é considerar uma outra maneira de conceber o conceito de "capital cultura". Ou seja, a proposta é ampliar seu entendimento, contudo garantindo o sentido que o qualifica como recurso, como um novo elemento de poder e diferenciação social. Embora em Os três estados do capital cultural Bourdieu (1998) explicite e construa uma definição para as três modalidades deste conceito - capital cultural incorporado, capital cultural objetivado e capital cultural institucionalizado ${ }^{3}$-, referindo-se notadamente à familiaridade ou experiência cultural dos segmentos médios e de elite, e neste sentido baseados sobretudo em uma cultura familiar e escolar distintiva, considero importante registrar que, ao formular o conceito, Bourdieu não desconsidera a existência dos grupos populares na disputa pela cultura legítima. $\mathrm{O}$ que ele afirma é que as diferenças de acesso à cultura e de aquisição desta entre os grupos sociais conferem aos mais privilegiados um poder real e simbólico que os habilita a apresentar os melhores 
desempenhos escolares. Para Bourdieu os segmentos populares não estão fora das disputas e dos conflitos de ordem cultural ${ }^{4}$ instaurados nas sociedades modernas. ${ }^{5}$ A própria concepção de sociedade de Bourdieu considera as tensas relações de interdependência entre os grupos sociais (Bourdieu, 1982). ${ }^{6}$ Neste sentido, para este autor os segmentos populares não são destituídos de recursos que os habilitam a participar das lutas simbólicas. Ao contrário, Bourdieu enfatiza que a desigual distribuição desse recurso raro estimula o conflito. Imposta pelas classes letradas e dominantes como sendo a cultura legítima, a cultura culta precisa ser sistematicamente valorizada por um conjunto de estratégias e rituais de consagração (exames de seleção, diplomas, formaturas, álbuns de formatura, becas etc.) para que seja legitimamente aceita e reconhecida por todos.

Posto isto, para uma melhor compreensão do conceito de "capital cultural" nos segmentos populares, proponho focalizar a heterogeneidade das configurações familiares estudadas a fim de contextualizar suas vivências. Creio que seria necessário observar os grupos populares em suas singularidades cultural, moral e ética, extraindo de suas vivências os usos variados que fazem da apropriação de outras formas de cultura, sejam elas legítimas ou não. ${ }^{7}$

Proponho aqui circunstanciar a variedade de situações encontradas entre as famílias pesquisadas, em que um incentivo, uma disposição ante a apreensão de informação pôde assumir o papel de elemento distintivo uma vez que essa informação teve o potencial de transformarse em conhecimento. ${ }^{8} \mathrm{Ou}$ seja, a) considerando esta "disposição" ou abertura a todo tipo de informação como uma estratégia de aquisição de cultura, seja ela em sua expressão escolar ou não, b) considerando o produto dessa estratégia um recurso construído a partir de investimentos diversos, c) não vendo esse recurso apenas como uma prerrogativa de segmentos privilegiados, d) bem como considerando as condições de sua apropriação e uso, creio que é possível ampliar o entendimento do conceito de "capital cultural", pondo em evidência sua complexidade. Explorando a dinâmica de criação desse capital e concebendo-o como uma forma de recurso, em constante construção, não pertencendo objetivamente ao indivíduo, contudo caracterizandoo e habilitando-o distintivamente em algumas circunstâncias sociais, ${ }^{9}$ é possível então historicizar ${ }^{10}$ e contextualizar sua utilização em diferentes segmentos sociais. 
Um novo capital cultural: pré-disposições e disposições à cultura...

A interdependência de recursos informais - a construção de um novo capital cultural

De uma certa forma, Bernard Lahire contribui também para visualizar o uso prático dos recursos construídos, consciente ou inconscientemente, como um capital cultural. Em uma outra perspectiva, ${ }^{11}$ mas dialogando também com o conceito, e enfatizando a heterogeneidade das experiências de socialização dos grupos populares, Lahire, em Sucesso escolar nos meios populares (1997), alerta para as possibilidades e condições de utilização desse novo recurso social. Considera que a presença objetiva de um capital cultural só terá sentido se este for colocado em condições que tornem possível sua "transmissão". Para ele, não basta uma criança estar cercada de objetos ou circular em ambientes estimulantes do ponto de vista escolar. É preciso estar atento para as modalidades efetivas de "transmissão" destas disposições culturais (Lahire, 1997, p. 338). Segundo este autor, as competências e os estímulos relativos ao acúmulo de capital cultural podem não surtir efeito quando não encontrarem situações para que sejam postos em prática. $\mathrm{Na}$ verdade, mesmo tendo baixo capital cultural, a transmissão de uma outra forma de valorizar o trabalho escolar deve ser considerada. Ter ou não ter acesso aos bens da cultura escolar ou informal não nos fala sobre as possibilidades de transmissão, não nos ajuda a compreender as condiçôes que efetivamente propiciam a apropriação de disposições culturais. Lahire (1997) alerta também para a necessidade de se reconsiderar ainda a noção de "transmissão", pois ela não esclarece o trabalho de apropriação e de construção efetuado pelos indivíduos. Não consegue apreender a inevitável transformação do "capital cultural" no processo de "outorgação" de uma geração para outra (...). Sendo ainda esta noção mais inadequada para conceber as freqüentes situações em que algo se "transmite" - ou melhor, se constrói - sem que nenhuma intenção pedagógica tenha sido visada (...) (Lahire, 1997, p. 341).

Nesse mesmo livro, Lahire, dando continuidade a suas reflexóes, oferece algumas idéias a respeito do processo de transmissão cultural, as quais se tornam notadamente interessantes para este estudo. Trabalha especificamente com a) as formas familiares da cultura escrita, b) as condiçōes e disposiçōes econômicas, c) a ordem moral doméstica, d) as formas de autoridade familiar e, por último, e) as formas familiares de investimento pedagógico. Ou seja, para o desenvolvimento do argu- 
mento deste artigo, saliento que Lahire, ao considerar cinco temas que organizam as análises das configuraçôes familiares de estudantes com sucesso escolar improvável, abre espaço para outras abordagens sobre os mesmos temas.

Considero que a originalidade de sua reflexão está em explorar com cuidado a complexa rede de determinação dos fatores relativos ao sucesso escolar dos segmentos populares. Assumindo uma nova perspectiva metodológica, Lahire revela uma abordagem circunstanciada da interdependência de elementos nas configurações familiares e escolares que explicariam, em tese, um sucesso escolar improvável. Entretanto, embora ainda sendo fiel às suas contribuições, gostaria de apresentar aqui uma outra configuração. Isto é, considero necessário chamar atenção para outras formas familiares de acesso à cultura, além da escolar, bem como às condições de estabilidade psicológica vivida pelas famílias brasileiras pesquisadas. ${ }^{12}$

Creio, contudo, que seria interessante explicitar, primeiramente, o conjunto de variáveis favoráveis ao sucesso acadêmico de uma maneira geral, tanto entre os alunos brasileiros como entre os franceses, para depois, em um segundo momento, apresentar as especificidades do contexto estudado no Brasil.

Compondo as configurações familiares

A ordem moral doméstica e as formas de autoridade familiar são, segundo Lahire (1997), importantes elementos que compõem a organização das famílias. O autor entende a ordem moral como um tipo de disposição que se aprende no exercício da socialização. Ou seja, é uma predisposição à obediência, à aceitação sem revolta às propostas educativas concretizadas nos ambientes escolares mas que, por certo, são adquiridas anteriormente no eixo familiar. A organização doméstica refletida nos horários rígidos das refeições, nos horários de ida e volta à escola, com ou sem o acompanhamento paterno/materno, nos momentos da lição de casa e/ou do lazer, são fortes elementos estruturadores de uma vida regrada segundo princípios de uma moral do bom comportamento.

$\mathrm{Na}$ falta de um domínio com relação aos conhecimentos escolares, uma socialização baseada na valorização da disciplina e da obediên- 
Um novo capital cultural: pré-disposições e disposições à cultura...

cia parece ocupar um papel de destaque nas famílias investigadas tanto por Lahire como por mim. E, como bem coloca este autor, a organização moral e material em casa pode refletir na escolaridade dos filhos porque é indissociavelmente uma ordem cognitiva. Gestão de um interior e gestão interior são atividades que caminham de forma paralela. Uma estrutura familiar material e temporalmente ordenada transmite, de maneira inconsciente, métodos de organização nas estruturas cognitivas ordenadas, predispostas a funcionarem como estruturas de classificação do mundo (Lahire, 1997, p. 26-27).

Simultaneamente a este sistema doméstico calcado na disciplina de uma rotina diária, é preciso estar atento também para as questóes relativas às formas de autoridade familiar. Se a organização de um interior favorece a organização cognitiva dos sujeitos, poderia afirmar também que a existência de uma autoridade paterna/materna vivida com legitimidade pode certamente refletir na aceitação da autoridade vinda da escola. Um aprendizado familiar baseado na presença de figuras seguras de sua posição de autoridade bem como um trabalho pedagógico em sua confiabilidade parecem ser importantes neste processo de socialização. A linearidade dos procedimentos, a similaridade dos códigos de convivência entre pais e filhos e entre autoridades escolares e alunos são condições que possibilitam uma harmonia de propostas, ou seja, uma coerência de projetos pedagógicos que podem ajudar em uma maior produtividade escolar. Para os objetivos deste artigo, seria importante salientar que a coincidência de projetos educativos entre a família e a escola foi, portanto, um importante fator de socialização para o sucesso acadêmico nos alunos pesquisados (Dubet, 1996).

É preciso estar atento também para as formas familiares de investimento pedagógico. Elas se referem ao empenho da família em um projeto de ascensão social via sistema de ensino. São práticas relativas à procura por uma escola particular ou por uma melhor escola pública da regiāo, ou mesmo no oferecimento de condições propícias aos estudos na compra de livros e material didático. É possível observá-las também na valorização do trabalho da escola ou na participação familiar nas propostas acadêmicas e até na concessão de tempo para a dedicação aos estudos, como mecanismos presentes nas configuraçôes familiares que se diferenciam por criar estratégias pedagógicas informais.

Lahire chama atenção ainda para as condições de estabilidade econômica como um fator tranqüilizador importante no universo das 
configurações familiares. Ou seja, uma certa tranqüilidade, uma relativa distância das emergências da sobrevivência material. Não obstante, pude observar que, ainda que o fator econômico não seja uma constante entre as famílias investigadas, uma reserva financeira sempre assegurada para a manutenção de uma organização doméstica está bastante presente. Uns com casa própria, outros com salários pequenos sempre disponíveis, a ajuda de familiares, ou duplas jornadas de trabalho para ambos os pais são circunstâncias que colocaram os alunos brasileiros pesquisados em situação privilegiada com relação às demais famílias dos segmentos populares.

Entretanto, embora creia que este elemento seja de fato de fundamental importância para a configuração de um eixo familiar estável, gostaria de acrescentar um outro fator de estabilidade. Poderia chamálo de condições e disposiçõoes dialógicas, ou seja, uma estabilidade de natureza psicológica também fundamental para garantir uma estrutura familiar com relaçóes predispostas ao diálogo, à conversa, a uma abertura para trocas de experiências. Uma configuração familiar em que se valoriza o conforto psicológico, a segurança afetiva, o reconhecimento de emoçõos e dificuldades ao longo da trajetória de crescimento dos filhos. Condições que certamente favoreceram o contato, a troca de estímulos e, portanto, a transmissão mais assegurada de valores culturais identitários. Neste sentido, presenciei condições ideais para a transmissão/interiorização de uma herança, de um capital moral, ético e cultural, valorizado pelos familiares.

Em outras palavras, creio que as condições e disposições de ordem material, aliadas às disposições de ordem psicológica, são fatores relevantes para se pensar biografias estudantis de sucesso. O diálogo cotidiano, a abertura para se ouvir e trocar informaçóes sobre o futuro, a sensibilidade para escutar sobre planos e investir em expectativas de carreira parecem ser comuns em alguns núcleos familiares. Foi possível identificar que o incentivo, o empenho, o crédito dado aos filhos com trajetória acadêmica valorizada (pela escola/ou não) foram pontos de apoio relevantes para o desenvolvimento de condições de confiança e de auto-estima por parte dos indivíduos investigados por mim.

É preciso alertar, entretanto, que, mesmo considerando que as condições de estabilidade material e psicológica sejam requisitos de igual importância, não considero contudo que essas condições favoráveis caminhem juntas, ou seja, coexistam simultaneamente nas confi- 
Um novo capital cultural: pré-disposições e disposições à cultura...

guraçôes familiares. Creio, ao contrário, que isso seria apenas uma possibilidade. Outros fatores poderiam estar atuando em conjunto, apontando então para novas biografias.

Por último, seria interessante refletir sobre as formas familiares de acesso à cultura. Lahire dá uma ênfase bastante grande aos hábitos de leitura e escrita das famílias. Entretanto sua ênfase recai não apenas sobre o aspecto da presença de tais habilidades e na familiaridade com elas, mas sobretudo recai sobre os efeitos de longo prazo que esses aprendizados precoces oferecem para o processo de socialização dos estudantes. Como vimos, Lahire chama atenção para o fato de que a existência de um capital cultural familiar - a posse de diplomas, o gosto pela leitura ou a freqüência a cinemas ou teatros - não determina, não garante mecanicamente a posse de cultura dos herdeiros. ${ }^{13}$ Segundo ele, é necessário estar atento para as formas de se relacionar com a cultura, as formas de transmissão, de apreensão e de apropriação dessa herança. É preciso então observar as condições desse processo de transmissão/ interiorização para entender esses recursos como responsáveis ou artífices de um sucesso.

Contudo, se as contribuições de Lahire nesta abordagem dos condicionamentos familiares de ordem cultural são inegáveis, gostaria de considerar que, onde ele chama atenção para as formas familiares de cultura escrita, pode-se acrescentar, de maneira complementar, uma outra forma de cultura. Chamo atenção para as formas familiares de cultura geral, sendo cultura geral aqui entendida não só a cultura escrita, mas a cultura visual, midiática, a cultura da rua e das vivências experimentadas virtualmente.

Creio que para o universo de investigação brasileiro foi necessário ampliar o tema da cultura escrita, proposta por Lahire, para as formas familiares de contato, apreciação e valorização de um universo de bens simbólicos ainda não legitimado, vivido e propiciado sobretudo nas formações sociais modernas e em desenvolvimento. Foi preciso estar atenta para as profundas transformações pelas quais as sociedades latino-americanas, e entre elas a brasileira, passaram e vêm passando desde meados da década de 1950, no que se refere ao acesso a bens da cultura de massa, e a seu papel altamente educativo e socializador (Ortiz, 1997[?]; Giddens, 1991 e 1994; Thompson, 1995; Hall, 1997; Kellner, 2001)..$^{14}$ 
Segundo Martín-Barbero (2000), falar das relações entre os meios de comunicação de massa e a escola, no universo cultural latino-americano, é observar uma nova experiência educacional que problematiza o monopólio do saber de uma cultura escolar e letrada: "O que portanto necessitamos pensar é a profunda compenetração - cumplicidade e complexidade de relaçóes - que hoje se produz na América Latina entre a oralidade, que perdura como experiência cultural primária das maiorias, e a visualidade tecnológica, essa forma de 'oralidade secundária’ tecida e organizada pelas gramáticas tecnoperceptivas do rádio e do cinema, do vídeo e da televisão" (Martín-Barbero, 2000, p. 47). Esta nova arquitetura cultural enseja então um descentramento nas experiências educativas. "Se já não se escreve, nem se lê como antes, é porque tampouco se pode ver, nem expressar como antes (...)" "O estouro das fronteiras espaciais e temporais que eles (os meios) introduzem no campo cultural, des-localiza os saberes, deslegitimando as fronteiras entre razão e imaginação, saber e informação, saber especializado e experiência profana (...)" (idem, ibid., p. 18).

Posto isto, faz-se necessário salientar que, no caso dos estudantes brasileiros, as maneiras de se relacionar e valorizar o saber da cultura da mídia surgiram nos depoimentos como importantes elementos que potencializaram uma pré-disposição familiar ao sucesso escolar, constituindo-se, pois, em um novo recurso ou capital. Em outras palavras, chamo a atenção para a particularidade da realidade cultural/educacional da modernidade vivida por esses estudantes, que põe à disposição de todos um saber, embora não tendo todos as mesmas condiçóes de apropriação. Saberes difusos propiciados pelas emissōes radiofônicas, pela programação da TV, pelas novelas, pelos fascículos, pela produção de programas didáticos, de entrevistas ou de conselhos médicos, que estão disponíveis e abertos para todos, seriam alguns exemplos de novas experiências educativas informais encontradas no universo pesquisado por mim.

De uma certa forma estou afirmando que as transformações de ordem cultural derivadas sobretudo da evolução da reprodutibilidade técnica dos textos e das imagens, tal como a diagnosticada por Walter Benjamin (1983) na década de 30 do século passado, colaboram com uma nova forma de apreender, usar e usufruir as produçôes culturais. Para este autor, a evolução técnica possibilita o despertar e a ampliação de nossa sensibilidade perceptiva e cognitiva. ${ }^{15} \mathrm{E}$ oferece novas con- 
Um novo capital cultural: pré-disposições e disposições à cultura...

dições de apropriação e recepção de representações e conhecimentos sobre o mundo. Neste sentido pode-se pensar na ampliação do potencial das capacidades reflexivas do indivíduo contemporâneo. ${ }^{16}$ As transformações quantitativas da difusão das mensagens - na forma de escrita ou na forma de imagens - aguçam a sensibilidade, ampliam a esfera e os espaços difusores de conhecimento (Morin, 1984; Martín-Barbero, 1995, 2000, 2002). Induzem para o aumento da capacidade reflexiva pois oferecem uma multiplicidade de saberes, constituindo-se numa nova realidade perceptiva e cognitiva das formações contemporâneas, para o indivíduo. Enfim, a maior difusão da informação pode ampliar o escopo de um conhecimento de experiências alheias, virtuais, distantes das relações face a face. ${ }^{17}$

Neste sentido, não seria mais possível pensar a educação em sua acepção tradicional, como instrução formal empreendida sobretudo nas instituições formais do ensino (Baccega, 2002; Citelli, 2002). É necessário estar aberto para outras formas de aprendizado, e aqui saliento aquele divulgado por agentes que estão fora dos círculos legitimamente reconhecidos como educativos. Embora com propostas distintas à escola ou à família, chamo atenção para o caráter socializador e educativo das produções da cultura das mídias no universo brasileiro pesquisado. Chamo atenção para sua capacidade de potencializar - em continuidade ou em ruptura - disposições com relação ao aprendizado adquiridas previamente no ambiente familiar ou escolar. Penso ser necessário circunstanciar então os usos desse material educativo, a fim de compreender a complexidade e a ambigüidade de suas realizaçôes (Setton, 1999, 2002).

Breve caracterização do grupo pesquisado ${ }^{18}$

Os dados apresentados neste artigo se referem sobretudo às entrevistas feitas com dez (10) alunos e algumas de suas mães, a fim de apreender a articulação das configurações familiares e o sucesso escolar apresentado. Após um exaustivo ${ }^{19}$ trabalho que visou à localização dos estudantes, escolhi aqueles que respondiam, em grande parte, às exigências da pesquisa. Ou seja, procurei alunos provenientes de lares com baixa escolaridade e baixos rendimentos econômicos, mas que apresentavam uma trajetória acadêmica de sucesso, a) já que tinham chegado ao topo da hierarquia estudantil - o ensino superior, b) em uma uni- 
versidade pública competitiva e c) freqüentavam cursos de elite (Setton, 2001). A intenção das entrevistas era identificar a articulação das estratégias educativas postas em prática pela família e pelo aluno.

O grupo de estudantes pesquisados demonstrou ser bastante heterogêneo. Composto por quatro mulheres e seis homens, com idades bastante variadas, nem todos poderiam ser caracterizados como provenientes das classes populares. Duas das alunas, Débora e Deby, embora tenham sido incluídas na amostra, destacavam-se pois vinham de lares em que a estabilidade socioeconômica tinha sido uma marca em suas vidas. Uma, filha de operário qualificado, torneiro mecânico, sempre contou com a ajuda de seu avô, marcando decisivamente um certo conforto econômico, se comparada com seus colegas. A segunda, filha de um tratorista, moradora de uma cidade do interior, sempre contou com uma rede de amigos que lhe possibilitou a circulação em ambientes sociais mais favorecidos. Os outros, sem exceção, têm origem em círculos sociais bastante humildes.

A formação escolar entre eles mostrou-se também bastante heterogênea. Dois estudantes apenas freqüentaram todo o ciclo fundamental e médio em escolas privadas. ${ }^{20}$ Assim, grande parte é oriunda da escola pública. Para os homens a realidade de um ensino técnico, no segundo grau, foi bastante significativa. Valendo-se de estímulos familiares (exceção feita à Paula), principalmente de suas mães, a trajetória de sucesso desses alunos, contudo, não foi vivida sem problemas. A maior parte deles teve outras experiências no ensino superior ou amargou alguns anos em cursinhos para vestibular.

Com relação a lazeres ou práticas culturais, foi possível detectar, como era de se esperar, um baixo consumo. Limitados financeiramente, quase todos tinham como seu único espaço de entretenimento a rua, o esporte e a TV; lazeres domésticos e bastante econômicos. ${ }^{21}$

Se, de um lado, destaca-se nesse grupo a figura materna e o constante diálogo entre esta e seus filhos, por outro, a presença da figura paterna é pouco comentada. Entretanto, a importância de irmãos mais velhos nesse processo é muito grande, já que muitos dos alunos pesquisados se valeram das experiências desses irmãos ou foram influenciados por eles. Vale chamar atenção, ainda neste particular, para o pequeno estímulo acadêmico dos professores nessa trajetória. Foi possível observar que estes têm um papel secundário na vida dos alunos pesquisados. Embora a auto- 
Um novo capital cultural: pré-disposições e disposições à cultura...

estima dos alunos, inclusive a auto-estima de seus familiares, com relação ao sucesso escolar, viesse sobretudo de uma avaliação positiva proveniente da escola, não apareceu em nenhum depoimento a figura de um mestre orientando ou ajudando nas decisões de leitura ou nas escolhas profissionais. É possível afirmar que a construção dessa trajetória foi feita por eles mesmos, a partir de modelos exteriores à escola e à família (Dubet, 1996). Desta, contaram com o apoio econômico, psicológico e pedagógico, o que já não é pouca coisa.

\section{Evidências empíricas}

Partindo de uma perspectiva singular de análise ${ }^{22}$ (Setton, 2002), procurei observar as articulações de sentido entre as estratégias pedagógicas identificadas nos depoimentos dos entrevistados. Seguindo as sugestóes de Lahire (1997), explorei as múltiplas configuraçôes entre as agências - família e escola - mas, sensibilizada com um conjunto de trabalhos que refletem sobre a emergência de uma nova ordem sociocultural no Brasil, após os anos de 1950, propus trabalhar a hipótese de que outras fontes educativas - as mídias - poderiam estar presentes, potencializando as trajetórias acadêmicas dos alunos investigados.

Cabe ressaltar que a importância da presença da cultura escrita e/ou do hábito da leitura, no universo familiar brasileiro pesquisado, é extremamente importante. Não diagnostiquei uma diluição ou perda de relevância da cultura letrada. Ao contrário, a cultura escrita não tem aqui um espaço reduzido, mas divide esse espaço com outras formas de linguagem provenientes da cultura de massa. O que se evidencia é que, junto da cultura letrada, foi possível detectar a presença de um outro tipo de cultura no cotidiano do estudantado que o pré-dispôs, junto com as estratégias familiares, a construir uma trajetória escolar meritória. Foi possível constatar que o acesso a um saber informal midiático, em ambientes familiares dóceis à cultura escolar, ampliou o referencial cultural dos alunos, potencializando um melhor desempenho escolar. As evidências estão inscritas nos discursos e nos depoimentos a respeito de assuntos que promoveram um entendimento sobre o universo cultural dos entrevistados. Nas questóes relativas ao lazer, ao tempo livre, aos hábitos de leitura ou escrita, ficou evidente a familiaridade de todos com o material posto à disposição pela cultura das mídias. 
Neste sentido, vale ressaltar que foi possível registrar várias experiências de contato precoce com o material escrito. Ora herdeiros de práticas de leitura entre seus familiares, pais, mães ou irmãos mais velhos, ${ }^{23}$ ora sem referências familiares, ${ }^{24}$ a presença da leitura ou da cultura escrita está em quase todos os depoimentos. Para os objetivos deste artigo é importante ressaltar, como faz Martín-Barbero, que

o livro continua e continuará sendo a chave da primeira alfabetização formal que, em vez de se fechar sobre si mesma, deve hoje pôr as bases para essa segunda alfabetização que nos abre às múltiplas escrituras, hoje conformando o mundo audiovisual e da informática. Estamos diante de uma mudança nos protocolos e processos de leitura, que não significa, nem pode significar, a simples substituição de um modo de ler por outro, senão a articulação complexa de um e outro (...). (Martín-Barbero, 2000, p. 62)

Ressalto, contudo, que o curioso e particular ao universo brasileiro, suscitando um maior envolvimento investigativo, é que, junto desta forma específica de prática cultural - a cultura escrita -, outras de igual importância emergem dos relatos das vivências dos alunos e de seus familiares. Entre elas destaco a cultura propiciada pela cultura das mídias. Mais que isso, em muitos momentos foi possível observar que a cultura escrita não esta restrita à cultura letrada e escolar, dos livros clássicos ou indicados para o vestibular, mas a uma cultura escrita em versão mais vulgar, mais massificada, desvalorizada e deslegitimada, se pensarmos com critérios acadêmicos (Bourdieu, 1979, p. 59, 70, 83).

A presença de fascículos ${ }^{25}$ é bem freqüente nos depoimentos e se destaca nas respostas relativas à escolha de carreira e à seleção da faculdade a ser cursada.

Eu dizia a ela, você não vai entrar na USP e ela dizia: porque vou, porque vou, então você vai na banca, naquela época tinha aquelas revistas, fascículos do vestibular, e ela comprou todo mês, não me lembro, comprou aquelas revistas e estudava, estudava aquilo de cabo a rabo, porque não tinha orientação de ninguém... (Mãe da Magy)

Então a primeira opção que eu tive... fui buscar o Guia do Estudante que é uma revista especializada nisso, né? E... busquei as matérias, as disciplinas que tivessem mais afinidade, no caso seria mais humanas. (Ricardo)

A literatura best-seller surge nos relatos quando vão caracterizar seus envolvimentos com a leitura ou como tiveram acesso a um material pouco valorizado pela escola e ainda desconhecido pela família. 
Um novo capital cultural: pré-disposições e disposições à cultura...

Eu era associado ao Círculo do Livro e, naquela época de inflação e congelamento de preços, os livros ficaram num preço irrisório e eu comprava 3 ou 4 livros por mês, era mais best-sellers; na época não tinha muito método para escolher, eu lia de tudo, Sidney Sheldon, Stephen King... (Duda)

No que se refere às revistas em quadrinhos, ${ }^{26}$ as narrativas sobre seus usos são bastante heterogêneas. Elas estão presentes nas práticas de lazer que estimulam o conhecimento das letras e seu aprendizado, como também na socialização com os colegas e seu estímulo à imaginação.

Ah, agora chegou no ponto das revistas, ele junto com dois amigos quando ele era criança, ainda estudando, na quarta série até a oitava, eles inventaram até de escrever revistas em quadrinhos... eles pintavam, desenhavam e as revistinhas em quadrinhos; ele tem coleção em casa, tem caixas enormes guardadas, Mulher Maravilha, Homem-Aranha, Capitão América, tudo que saía na época, ele comprava nas bancas, às vezes ele me pedia, quando ele não trabalhava ainda... (Mãe do Otávio)

Eu sozinha... acredite se quiser, minha mãe nem tinha tempo para isso, ela trabalhava sem parar, então ela me deu revistinhas da Mônica, gibi, e me deu a cartilha Caminho suave, eu nunca me esqueci dos desenhos, hoje eu tenho os estudos, eu me lembro ainda de estar sentada numa balança lendo a cartilha... do meu jeito, lendo os quadrinhos, eu aprendi realmente sozinha.... (Magy)

$\mathrm{O}$ acesso aos jornais e o interesse pela sua leitura são lembrados nas questões relativas à iniciação às primeiras letras e à conseqüente curiosidade de poder discutir e participar das decisóes do mundo dos adultos.

Eu tive acesso, meu pai era manobrista e trazia sempre o jornal diário da empresa em que ele trabalhava na época. Tinha o jornal da recepção que ficava para todo mundo e no fim do dia ele trazia, eu tinha interesse..., eu acabava vendo aquilo lá, tanto que eu aprendi ler antes de entrar na escola, com 4 anos eu lia, também por estímulo da minha mãe e por curiosidade, via muita TV também, noticiário e a programação infantil que na época tinha mais qualidade... Era um jornal diário mesmo, ele trazia, já estava requentada a notícia, 8 ou 10 da noite, mas eu tinha interesse de, eu tinha lá meus $4 / 5$ anos, eu me lembro deste jornal.... (Israel)

Eu pesquisava... Guia do Estudante, revistas... na época a empresa em que eu trabalhava assinava a Folha, não sempre..., toda quinta-feira tinha a "Folha Vestibular" que eu dava uma folheada. Então eu fui assim procurando justamente aquela imprensa especializada. (Wago) 
Ler periódicos parecia ser uma constante entre eles. Embora o acesso a eles fosse defasado, pois compravam revistas de segunda mão e por um preço mais em conta, apresentam-se como espaços de divulgação de idéias e notícias que os ajudaram em muitas das questóes nas quais se viam, mas que não recebiam respostas por parte da família el ou da escola.

As revistas apareciam... tinha uns irmãos mais velhos, por parte de pai, eles traziam coisas da rua, revistas, essas coisas, e eu também acabava absorvendo isso aí. Eu lembro da revista Placar, que era de futebol, e meu irmão costumava trazer muito Jornal da Tarde, aí, passei... li muito Jornal da Tarde por essa influência... ele também gostava de música, mas música internacional, então acabei tendo influência, procurando saber o que o cara queria dizer com a música, aí... já é um estímulo maior para você aprender... este negócio do inglês... da música começou ali, nos compactos simples do meu irmão. (Israel)

Isso eu não me lembro, eu lembro de ter pesquisado coisas semelhantes em manuais, eu não me lembro se era o Manual da FUVEST, eu acho que era. (Magy)

Por fim as mídias áudio e visuais. Embora a presença da TV e do rádio $^{27}$ seja lembrada com freqüência nos depoimentos de todos, os usos que fazem desses veículos são bastante heterogêneos. Para os objetivos deste artigo, cumpre lembrar que esses meios de informação podem ser altamente educativos pois cumprem a função de transmitir um conteúdo que é apropriado diferentemente pelos sujeitos, a partir de interesses e problemas particulares. Ou seja, nos depoimentos coletados observei que ora servem como mediadores de um saber difuso e pré-científico, ora como sistematizadores de conhecimentos escolares.

Eu sempre vi a minha mãe tendo a cabeça no lugar, não deixando meu pai gastar mais do que podia e minha mãe assim vendo programa na televisão, de médicos, então a única coisa que às vezes a gente fala, saber o nome das doenças, o que causa, o que não causa... muita coisa... ela ouve muito rádio... então eu sinto que, por mais que ela tenha parado de estudar na quarta série, o que ela sabe, a bagagem que ela tem, que ela buscou, ela aprendeu de escutar uma coisa, e de já aprender e guardar, e já querer saber mais... eu admiro muito a minha mãe, um monte de coisa a gente quer saber... como ela sabe? Porque ela ouviu no rádio ou na TV o médico falando, ou ela leu em algum lugar, ela ouviu e prestou atenção. (Deby) 
Um novo capital cultural: pré-disposições e disposições à cultura...

Comecei a fazer o cursinho da Poli aqui, e ela (a irmã) já... mas eu lembro que na época que ela fez vestibular ela estudava, ela assistia àquele programa "Vestibulando", que passava na Cultura, ela ficava anotando tudo direitinho e ela não teve a oportunidade que eu tive, ela não fez cursinho, meu pai não podia pagar cursinho para ela... (Breno)

Não, não. A leitura na família é algo que não é muito. Os meus pais não lêem... periódicos... o meu pai ele adora informativos, mas de TV.

Neste sentido, o que se observa é uma familiaridade com bens da indústria da cultura, um contato freqüente com produtos "desclassificados" do ponto de vista escolar (Bourdieu, 1979), encontrados nas bancas de jornal e não os comercializados em templos da cultura como as livrarias. Seja em perguntas relativas ao lazer,

Vai depender da época, mas eu sempre gostei de esporte, gibi, desde a infância, cinema, filmes de ação em geral... sempre a gente tem influência dos jornais, da TV da época. (Otávio)

Jogava um pouco de bola... mas eu ia no cinema também, costuma ir com os amigos... (Israel)

seja em questôes relativas aos modelos de conduta que fogem do universo paterno e escolar, ${ }^{28}$

Acho que veio dessa influência do... meus irmãos também depois ficaram assim rebeldes, não queriam dar dinheiro, queriam morar sozinhos, então eu prestava atenção nisso... né? Tinha um outro lado que não era só aquela orientação familiar, tinha um outro mundo... uma outra coisa, eu lia jornais, as revistas, a TV também fazia eu questionar, certo, acho que este questionamento vem daí. (Israel)

Acho que é uma ambição mesmo, eu nunca gostei de ser pobre, de ter pouco dinheiro e eu sabia que se eu continuasse lá eu não conseguiria sair do lugar. Tudo o que você vê na TV, nas revistas, nos livros, esses best-sellers, todos têm uma fórmula muito comum, assim, rico e bem-sucedido, só ele consegue tudo. Acho que isso me marcou, eu era muito jovem quando comecei a ler isso, tinha uns 15 anos e às vezes, até hoje, isso me incomoda... se eles conseguiram isso, por que eu não posso conseguir? Eu também posso conseguir isso. (Duda)

bem como nas questôes que versam sobre aspectos da vida cotidiana da família,

Nós conversamos muito em casa, sabe, sobre as coisas do mundo, e ver TV, mas falando, e eu sou a primeira a falar, às vezes a gente está vendo a novela, 
eu estou dando palpite, sabe, é uma coisa que eu acho que eu fui adquirindo de ouvir dos meus pais, minha mãe que fala muito, que tem opinião própria, e sempre em casa teve conversas, discussão. (Deby)

Eu sempre li muito, sempre procuro ler, leio jornal, assisto também TV junto com elas. Quando assistimos um programa que tem alguma coisa que eu acho que não é certo, a gente comenta. (Mãe da Deby)

a forte presença das mídias, como provedora de informações e com potencial de produzir um novo capital cultural, chama a atenção. Ora substituindo a escola, ora entretendo, mas exercendo um papel educativo, as mídias parecem, de fato, desempenhar um papel importante na trajetória acadêmica desses alunos, sobretudo se aliada às estratégias pedagógicas tradicionais explicitadas no início da argumentação.

\section{Considerações finais}

O objetivo deste artigo foi refletir sobre as estratégias pedagógicas que potencializaram trajetórias de sucesso acadêmico entre alunos provenientes de segmentos com baixa escolaridade. Teve a intenção de apontar a complexa rede de fatores relativos ao sucesso escolar de um grupo de estudantes brasileiros. Atenta para as variadas formas de se relacionar com os bens da cultura, de transmiti-los e de se apropriar deles, ressaltei a particularidade de uma nova forma de aquisição cultural específica das formações contemporâneas. Entre os estudantes pesquisados, observei a existência de uma valorização com relação ao aprendizado escolar, mas também uma abertura para outras experiências de conhecimento e vida cultural, colocada à disposição pela virtualidade da informação na modernidade.

Dialogando com as contribuições de Lahire, propus compreender o sucesso acadêmico de alguns indivíduos segundo a articulação de um feixe de condicionamentos socioculturais. Além de fatores relacionados à esfera familiar e escolar, considerei a hipótese de que o estudante brasileiro investigado se socializa a partir da interdependência de sistemas híbridos construídos pelas instâncias família e escola, mas também por um sistema difuso de informações veiculado pela cultura das mídias.

Em outras palavras, nesta reflexão salientei que uma pré-disposição a práticas pedagógicas familiares, aliada ao acesso a um conheci- 
Um novo capital cultural: pré-disposições e disposições à cultura...

mento geral e midiático, pôde colocar à disposição, para alguns indivíduos - na falta ou na complementação de uma bagagem estruturada e oferecida oficialmente pelas instituições competentes -, a utilização dessas informaçôes como um recurso distintivo.

O importante, neste sentido, foi revelar que existem diferenças de várias ordens, principalmente de acesso aos bens da cultura, entre as famílias, que são responsáveis pela variação no aproveitamento escolar. Isto é, a posse de um capital cultural midiático, associado às estratégias pedagógicas de natureza diversa, é uma forma de expressar um ethos familiar predisposto a valorizar e incentivar o conhecimento formal e informal, importantes elementos para se alcançar um sucesso escolar. Em outras palavras, destaquei uma nova ordem de estratégias e/ ou práticas culturais que demonstraram uma abertura perante o aprendizado difundido por instituições ainda não consagradas como legítimas. Como bem afirma Lahire, ter ou não ter acesso aos bens da cultura escolar ou informal não nos fala sobre as possibilidades de transmissão, não nos ajuda a compreender as condições que efetivamente propiciam a apropriação de disposições culturais. É preciso, pois, observar várias situações em que algo se transmite, ou melhor, se constrói, sem nenhuma intenção pedagógica.

Posto isto, chamei atenção para a capacidade de os bens culturais provenientes das mídias potencializarem, em continuidade ou em ruptura, disposições com relação ao aprendizado, adquiridas previamente no ambiente familiar e escolar. E, conseqüentemente, acabei por problematizar os usos da cultura de massa, contrariando pesquisas (Postman, 1999; Khel, 1995, 2000) que generalizam os efeitos das mídias como sendo responsáveis pelos males culturais do mundo moderno.

Considero que ampliar a abordagem sobre as formas de se relacionar com os saberes culturais difusos corrobora pensar os usos da cultura, reflete sobre as formas de vivenciar e se orientar ante uma nova forma de circularidade da informação. Contribui e esclarece parte das experiências vividas pelos estudantes investigados, ao permitir pensar uma trajetória acadêmica e social sendo construída pela mediação de uma cultura constituída fora do espaço escolar, que está pulverizada, mas, no entanto, presente e que pode servir como recurso el ou capital. ${ }^{29}$ 
Neste sentido, esta abertura para experiências e informaçōes externas e difusas pode também predispor a uma atitude mais reflexiva, mais interpretativa sobre a vida e sobre os saberes. Tal como a cultura escrita, que predispõe os indivíduos a uma prática, a uma ação com crítica, a expressiva difusão da informação pode também, conjuntamente, oferecer uma possibilidade de reação reflexiva e interpretativa entre os sujeitos (Lahire, 1997; Giddens, 1991; Benjamin, 1983). Abrindo espaço para o contato com outras vivências e competências, a circulação de mensagens propiciada pelas mídias pode estimular o aprendizado de novos saberes, contribuindo para a aquisição de uma outra forma de capital cultural. Recurso não mais visto segundo a conceituação tradicional de Bourdieu (1979, 1998). Uma herança específica e objetivada em diplomas e práticas culturais legitimadas, mas um conhecimento, um capital não-escolar, um recurso mais amplo, pulverizado, heterogêneo, não obstante um recurso que predispóe e potencializa o indivíduo a enfrentar novos desafios e vencer os limites de uma experiência estreita relativa a um universo familiar e escolar. É possível assim pensar um capital cultural com outra significação, um capital cultural dos desfavorecidos ${ }^{30}$ apreendido informalmente em heterogêneas experiências, em vários espaços do convívio social, notadamente no contato com informaçóes colocadas à disposição pelos meios de comunicação de massa.

\section{Recebido em setembro de 2004 e aprovado em fevereiro de 2005.}

\section{Notas}

1. Este trabalho faz parte do relatório final, entregue à FAPESP, da pesquisa intitulada Trajetórias acadêmicas: um estudo sobre as estratégias de transformação da ordem. Essa pesquisa foi empreendida entre os anos de 2000 e 2002, na École de Hautes Études en Sciences Sociales, Paris, França, e na Faculdade de Educação da Usp. Desdobramento de uma investigação sobre o perfil sociocultural e acadêmico dos alunos dos 23 cursos de humanidades do campus de São Paulo, a pesquisa deu prioridade a um estudo qualitativo sobre alunos de origem popular que ingressaram nos cursos considerados de elite - administração, arquitetura, editoração, relações públicas, direito, rádio/TV. Mais informações sobre os critérios de classificação dos cursos, consultar Setton (2001).

2. Seria interessante considerar aqui as contribuições de Ortiz em Mundialismo e cultura (1994). Para ele a modernidade traz novos valores, novos padróes globais e hegemônicos que conferem prestígio àqueles que os interiorizam. As formas tradicionais de cultura, entre elas as veiculadas pela escola, por exemplo, deixariam de ser as únicas formas de distinguir os grupos sociais. Neste sentido, o acesso diferenciado aos bens de consumo midiáticos poderia servir como elemento hierarquizante entre os grupos e segmentos sociais diversos. 
3. Capital cultural incorporado, sob a forma de disposições duráveis do organismo; capital cultural objetivado, sob a forma de bens culturais materiais; e o capital cultural institucionalizado, sob a forma de diplomas e titulação.

4. Por "conflitos de ordem cultural" denomino a disputa pela imposição de uma cultura hegemônica.

5. É possível identificar uma polêmica sobre este assunto: Passeron (1995), Grignon \& Passeron (1989), entre outros, contestam esta leitura sobre o conceito de "capital cultural", pois crêem que se trata de uma visão legitimista da cultura. Ou seja, os segmentos populares, neste sentido, seriam caracterizados por uma cultura da falta, da ausência. No entanto, os mesmos autores concordariam com a hipótese de que diferentes formas de capital cultural entre os segmentos populares podem impor uma diferenciação interna entre eles. Neste sentido, a questão central é mais que a simples posse de um certo tipo de capital, mas as diferentes maneiras de se apropriar dele.

6. "Uma classe não pode jamais ser definida apenas por sua situação e por sua posição na estrutura social, isto é, pelas relações que mantém objetivamente com as outras classes sociais. Inúmeras propriedades de uma classe social provêm do fato de que seus membros se envolvem deliberada ou objetivamente em relações simbólicas com os indivíduos das outras classes, e com isso exprimem diferenças de situação e de posição segundo uma lógica sistemática, tendendo a transmutá-las em distinçôes significantes" (Bourdieu, 1982, p. 14).

7. Seria interessante salientar que, se o domínio da cultura culta e letrada estivesse garantido, não precisaria de uma série de estratégias de legitimação e consagração. Esse domínio se forjaria por si. É neste sentido ainda que a cultura não legitimada dos segmentos populares precisa ser a todo tempo estigmatizada como pobre e grotesca (Bourdieu, 1996b).

8. Faço uma distinção entre informação e conhecimento. Apoiando-me em Baccega (2001, p. 23-24), entendo o sentido da noção de conhecimento como "processo que prevê a condição de reelaborar o que vem como dado (informação), possibilitando que não sejamos meros reprodutores (...)".

9. "Essas propriedades, capitais ou recursos não são coisas que determinam o indivíduo, mas realidades encarnadas em seres sociais concretos que, por meio de seu modo de relacionamento com a criança, irão permitir, progressivamente, que constitua uma relação com o mundo e com o outro" (Lahire, 1997, p. 18).

10. O uso da palavra historicizar provém da necessidade de mostrar que o processo histórico pode eleger o uso de alguns elementos na qualidade de recursos como pode também desvalorizar aqueles que eram legítimos em períodos anteriores.

11. É importante colocar que Lahire $(1997,1998,1999)$ já há um tempo vem se dedicando a uma série de reflexões críticas a respeito da teoria do social de Pierre Bourdieu, mais especificamente ao conceito de habitus deste autor.

12. Cabe ressaltar aqui uma série de estudos que discutem o sucesso acadêmico dos meios populares no Brasil como na França. Em recente publicação Nogueira et al. (2000) registram experiências de pesquisa que trabalham com o referencial teórico de Lahire, entre outros, e articulam as relações de interdependência entre família e escola. Embora todos eles tenham sido importantes para a problematização dos objetivos deste artigo, em razão do limite deste espaço, não serão citados, pois de uma certa forma discutem, em síntese, o que recupero das discussões de Lahire. Além disso, nenhum deles trabalha as mídias como uma importante matriz socializadora. Entre os estudos franceses, saliento a contribuição de Bernard Lahire, pois ele, de forma original, pensa o sucesso acadêmico dos meios popu- 
lares como resultado de um feixe de condições culturais favoráveis, diferentemente de outros autores, tais como Jean-Paul Laurens (1992); Jean-Yves Rochex (1995); Z. Zéroulou (1988), entre outros, que enfatizam apenas um ou mais aspectos favoráveis ao sucesso acadêmico.

13. "Herdeiros" é a palavra utilizada por Bourdieu para designar um grupo de indivíduos que têm o privilégio de pertencer a famílias as quais possuem recursos culturais e materiais que possibilitam e/ou potencializam a transmissão de um capital cultural; nome de seu livro já citado neste trabalho (Bourdieu \& Passeron, 1964).

14. Penso que a sociedade brasileira, embora esteja inserida na complexidade da rede cultural possibilitada pela globalização, conectada pelas tecnologias informativas, eletrônicas e digitais, ainda não conta com um sistema de ensino capaz de integrar a todos em uma cultura comum de qualidade.

15. "Aprofundando a questão: há anos me pergunto por que os intelectuais e as ciências sociais na América Latina continuam majoritariamente padecendo de um pertinaz 'mau-olhado', que os faz insensíveis aos desafios culturais que a mídia coloca, insensibilidade intensificada diante da televisão" (Martín-Barbero, 2000, p. 23).

16. Neste sentido W. Benjamin oferece uma interpretação positiva sobre o fenômeno da reprodução das mercadorias culturais, oferecendo um contraponto às análises de outros teóricos como Adorno \& Horkheimer (1996), embora não descartasse o uso ideológico do potencial tecnológico.

17. As contribuições de Anthony Giddens (1991) sobre os sistemas peritos possibilita também pensar a particularidade do contexto cultural/educacional contemporâneo. Ou seja, definindo sistemas peritos como um tipo de discurso e de saberes especializados, usados de maneira difusa e descontextualizada, formas de interpretar e orientar as condutas, Giddens (1991, 1994) considera um novo sistema de idéias e referências de vida, do qual os indivíduos têm condição de fazer uso na falta de um conhecimento estruturado e adquirido nas instituições formais de ensino.

18. Segue em anexo a ficha com mais informações sobre os alunos, como sexo, idade, profissão paterna e materna, escolha de curso etc.; ressalto que os nomes apresentados são fictícios.

19. Entre os 100 alunos que manifestaram desejo em participar da etapa das entrevistas, apenas um terço deles mantinha telefones ou e-mails atualizados. Entre aqueles com que consegui fazer contato, apenas 20 se dispuseram a se envolver nessa segunda etapa. No entanto, poucos foram aqueles que estavam afinados com os objetivos da pesquisa e que se mostraram disponíveis no momento da solicitação.

20. O que não garante uma qualidade de ensino, já que em muitos momentos os alunos alertavam sobre a defasagem de conteúdos em disciplinas de exatas. A esse respeito consultar Whitaker, 1989.

21. Em várias pesquisas realizadas, Setton confirma um baixo consumo cultural entre os segmentos pesquisados. Entre eles destacam-se os professores (1989), pequenos e médios proprietários (2004), e estudantes (1997).

22. Por "perspectiva particular de análise" entendo um esforço em não absolutizar um fator de determinação. Trata-se de empreender uma perspectiva relacional a fim de apreender a relação de interdependência entre os fatores.

23. “(...) embora não tenha curso superior, nem segundo grau, ele (o pai) se interessa muito, gosta de ler, de se informar, minha mãe também, sem dúvida, minha mãe gosta de livros,

Educ. Soc., Campinas, vol. 26, n. 90, p. 77-105, Jan./Abr. 2005

Disponível em <http://www.cedes.unicamp.br> 
ela lê mais que meu pai. Meu pai gosta de ler livros mais históricos, que conta alguma coisa... Minha mãe já se interessa por romance, os livros que eu também gosto de ler, jornal, livros do vestibular" (Débora); "Tá, meus pais não curtem muito ir a museus, bibliotecas, e ler, muito raramente, ela (a mãe) não lê nada mesmo, e meu pai, ele lê mas ele não lê livros assim... como eu vou te dizer, lê livros de auto-ajuda. Eu lembro porque eu lia os livros que o meu pai lia, então eu acabei lendo livros que eu acho engraçado, eu não sei como eu lia, tinha livros assim superadultos, a sexualidade não sei das quantas..." (Magy); "Eu acho que a minha irmã influenciou muito nessa minha maneira de gostar de estudar. Apesar de ter ido para essa área de biológicas, sempre gostou muito de ler, eu sempre via minha irmã estudando muito, e lendo muito antes de ir dormir; ela lia algum livro e sempre me lia poesia do Fernando Pessoa..." (Deby).

24. "Eu lia muito, eu lia de tudo, eu acho que ninguém me indicava, nas bibliotecas eu não... eu ia à biblioteca da escola, depois passei a ir sozinha, eu lia livros, mas assim tipo romance, lia literatura, lia ficção científica, lia romance clássico. Meus pais não gostam, eles não lêem, meu pai acha até que eu lia demais, não tem isso em casa, inclusive eu não tenho livro nenhum em casa, nem meus irmãos, só livros didáticos assim..." (Paula); "Não, ela (a mãe) lia alguma coisa, esses romances açucarados tipo Júlia, só que depois, com o tempo, ela perdeu esse hábito. E meu pai nunca se interessou. Eu freqüentava, sempre fui rato de biblioteca, desde a época da quinta série, quando montaram a biblioteca nessa escola em que eu estudava" (Duda).

25. Nas estratégias de incentivo aos estudos esses fascículos estão presentes também. Vejamos: "Não, não falo, achei muito difícil, eu quando estava na época do colegial, meu pai comprou um curso de inglês desses vendedores que vendem de porta em porta. Esses cursos básicos de 12 livrinhos e eu estudei em casa, completo, mas não saí falando inglês, mas deu, já me deu uma base" (Duda).

26. "Eu sei que quando chegou nos 3 anos e meio ela já lia. Isso não começando com a-e-i-o-u - não começou assim, não, lia palavra inteira, ensinava o que estava ali, num sei se você se lembra das revistinhas da Mônica. Ela tinha secura por aquilo ali...” (mãe da Magy).

27. "Não, não. A leitura na família é algo que não é muito. Os meus pais não lêem... periódicos... o meu pai ele adora informativos, mas de TV. Ele adora jornais, né, também assiste um pouco de ficção, mas principalmente filmes e western (...)" (Wago); "Nunca foi de brincar na rua, então tinha aqueles programas da TV Gazeta, você não deve se lembrar porque eu acho que não é da sua idade, era tipo acho 11 horas ou meio-dia, uma coisa assim, e tinha uma professora, agora não se vê, não era uma professora que ensinava mostrando produtos para vender, nada disso, era uma professora, mesmo, ótima, dava aula na TV, e era assim só para o prézinho, ela ensinava com aquelas figurinhas, pintava, mandava comprar o material, eu comprava, ia todo dia na banca de jornal buscar a Gazeta que chamava Gazetinha, que vinha um folheto, vinha dentro, então comprava aquilo para poder acompanhar a lição, porque ela passava, a professora passava, a Magy devia ter 3 a 4 anos, foi um ano e tanto isso, passava os desenhos, tinha historinhas, historinhas até do nome de hemácias, leucócitos, tudo isso aí... sumiu essa professora" (mãe da Magy).

28. "Acho que veio dessa influência do... meus irmãos também depois ficaram assim rebeldes, não queriam dar dinheiro, queriam morar sozinhos, então eu prestava atenção nisso... né? Tinha um outro lado que não era só aquela orientação familiar, tinha um outro mundo... uma outra coisa, eu lia jornais, as revistas, a TV também fazia eu questionar, certo, acho que esse questionamento vem daî" (Israel); "Acho que é uma ambição mesmo, eu nunca gostei de ser pobre, de ter pouco dinheiro e eu sabia que se eu continuasse lá eu não conseguiria sair do lugar. Tudo o que você vê na TV, nas revistas, nos livros, esses best-sellers, todos têm 
uma fórmula muito comum, assim, rico e bem-sucedido, só ele consegue tudo. Acho que isso me marcou, eu era muito jovem quando comecei a ler isso, tinha uns 15 anos e às vezes, até hoje, isso me incomoda... se eles conseguiram isso, por que eu não posso conseguir? Eu também posso conseguir isso" (Duda); "Eu me lembro agora, na verdade eu adorava ler biografias, então eu tinha Beethoven, na verdade eu já esqueci, esses fascículos de música que eu tinha bastante. Eu lembro de discos que tinham a biografia dentro, então eu acho que fui eu mesma que comprei quando ganhei um toca-discos, eu gostava de biografia desde pequena. Me lembrei agora. Tinha duas enciclopédias em casa, eu lia as enciclopédias inteiras, já viu... aí você fala que é raro entrar em uma faculdade de elite, era pior a situação (do Beethoven), o cara era surdo, era doente, tinha uma porção de coisas, claro, claro que era Beethoven, provavelmente não tinha dinheiro, puxa, era um gênio. Então eu falei, eu quero ser igual, foi mais ou menos isso, eu quero ser igual, eu sempre gostei de biografias...” (Magy).

29. Pode-se argumentar, como o fez Bourdieu (1997), entre outros, que os tipos de informações veiculados pelos meios de comunicação de massa são selecionados e produzidos segundo critérios que não respondem à lógica da ciência e que essas transmissões ficam sujeitas às imposiçôes, temporal e filosoficamente, do mercado midiático. No entanto, embora estas afirmaçōes, a meu ver, sejam válidas, creio que é preciso salientar, como ele já o fez (1979), que a mídia como produtora de sentidos e saberes não tem o monopólio na formação das consciências. Age simultânea e paralelamente com outras agências da educação - a família e a escola. Pode-se argumentar também que o acesso a essas instâncias seja heterogêneo e que parcela significativa tenha como grande veículo pedagógico as mídias. Neste sentido, argumentaria que a questão de base não reside no caráter parcial, fragmentado e politicamente comprometido dos meios, esta é uma realidade que parece não levantar mais controvérsias. Não obstante creio que é preciso considerar que a questão não se esgota nas críticas que se possa fazer aos meios, como também exigir e esperar deles um discurso a que não se propõem. O importante, a meu ver, é primeiramente considerar a incapacidade das instâncias tradicionais da educação de proporem uma educação de qualidade a todos e, como decorrência, problematizarem os conteúdos midiáticos. Neste sentido, a hipótese aqui considerada, sobre a abertura de novos conhecimentos colocados à disposição pela circularidade na modernidade, parece ser válida.

30. Uso a palavra "desfavorecidos" neste contexto, no entanto o conhecimento de uma cultura geral também pode conferir aos segmentos de elite um recurso a mais que os distingue no interior dos grupos favorecidos. A este respeito consultar Bourdieu, 1982.

\title{
Referências bibliográficas
}

\author{
ADORNO, T.; HORKHEIMER, M. Dialética do esclarecimento. Rio \\ de Janeiro: Zahar, 1996.
}

BACCEGA, M.A. A construção do campo comunicação/educação: alguns caminhos. Revista USP, São Paulo n. 48, p. 18-31, 2000/2001.

BACCEGA, M.A. Televisão e escola: aproximações e distanciamentos. In: CONGRESSO BRASILEIRO DE CIENCIAS DA COMUNICAÇÃO, 25., 2002, Salvador, BA. Anais... São Paulo: Intercom, 2002. 
Um novo capital cultural: pré-disposições e disposiçôes à cultura...

BENJAMIN, W. A obra de arte na era de sua reprodutibilidade técnica. In: Benjamin, W. et al. Textos escolhidos. São Paulo: Abril, 1983. p. 165-196. (Os Pensadores)

BOURDIEU, P.; PASSERON, J.C. Les héritiers, les étudiants et la culture. Paris: Minuit, 1964.

BOURDIEU, P.; PASSERON, J.C. La distinction: critique social du jugement. Paris: Minuit, 1979.

BOURDIEU, P.; PASSERON, J.C. A economia das trocas simbólicas. São Paulo: Perspectiva, 1982.

BOURDIEU, P.; PASSERON, J.C. Razóes práticas: sobre a teoria da ação. Campinas: Papirus, 1996 a.

BOURDIEU, P.; PASSERON, J.C. A economia da trocas lingüísticas: o que falar quer dizer. São Paulo: EDUSP, $1996 \mathrm{~b}$.

BOURDIEU, P.; PASSERON, J.C. Sobre a televisão: a influência do jornalismo e os jogos olímpicos. Rio de Janeiro: Zahar, 1997.

BOURDIEU, P.; PASSERON, J.C. Escritos de educação. Petrópolis: Vozes, 1998.

CITELLI, A. Comunicação e educação: linguagem em movimento. São Paulo: SENAC, 2002.

DUBET, F. Sociologia da experiência. Lisboa: Instituto Piaget, 1996.

GIDDENS, A. As conseqüências da modernidade. São Paulo: Unesp, 1991.

GIDDENS, A. Modernidade e identidade pessoal. Oeiras: Celta, 1994.

GRIGNON, C.; PASSERON, J.C. Le savant et le populaire: miserabilisme et populisme en sociologie et en litterature. Paris: Seuil, 1989.

HALL, S. A centralidade da cultura: notas sobre as revoluções de nosso tempo. Educação \& Realidade, Porto Alegre, v. 22, n. 2, p. 15-46, 1997.

KELLNER, D. Cultura da mídia. Bauru: EDUsC, 2001. 
KEHL, M.R. Imaginário e pensamento. In: KHeL, M.R. Sujeito, o lado oculto do receptor. São Paulo: Brasiliense, 1995.

KEHL, M.R. Televisão e violência do imaginário. In: KHel, M.R. A $T V$ aos 50: criticando a televisão brasileira no seu cinqüentenário. São Paulo: Perseu Abramo, 2000.

LAHIRE, B. Sucesso escolar nos meios populares: as razões do improvável. São Paulo: Ática, 1997.

LAHIRE, B. L'homme pluriel. Paris: Nathan, 1998.

LAHIRE, B. Le travail sociologique de Pierre Bourdieu: dettes et critiques. Paris: La Découverte, 1999.

LAURENS, J.-P. 1 sur 500: la réussite scolaire en milieux populaires. Toulouse: Presses Universitaires du Mirail, 1992.

MARTÍN-BARBERO, J. Dos meios às mediaçôes: comunicação, cultura e hegemonia. Rio de Janeiro: UFRJ, 1995.

MARTÍN-BARBERO, J. Os exercícios do ver. São Paulo: SEnAC, 2000.

MARTÍN-BARBERO, J. La educación desde la comunicación: enciclopedia latinoamericana de sociocultura y comunicación. Buenos Aires: Norna, 2002.

MORIN, E. Cultura de massa no século XX: o espírito do tempo. Rio de Janeiro: Forense-Universitária, 1984. v.1.

NOGUEIRA, M.A. et al. (Org.). Família \& escola: trajetórias de escolarização em camadas médias e populares. Petrópolis: Vozes, 2000.

ORTIZ, R. Mundialismo e cultura. São Paulo: Brasiliense, 1994.

ORTIZ, R. O próximo e o distante: Japão e modernidade mundo. São Paulo: Brasiliense, 2000.

ORTIZ, R. Um outro território: ensaios sobre a mundialização. São Paulo: Olho d'Água, [1997?]

PASSERON, J.C. O raciocínio sociológico: o espaço popperiano do raciocínio natural. Petrópolis: Vozes, 1995. 
Um novo capital cultural: pré-disposições e disposições à cultura...

POSTMAN, N. O desaparecimento da infância. Rio de Janeiro: Graphia, 1999.

ROCHEX, J.-Y. Les sens de l'expérience scolaire: entre activité et subjectivité. Paris: Presses Universitaires de France, 1995.

SETTON, M.G.J. Professor: um gosto de classe. 1989. Dissertação (Mestrado) - Pontifícia Universidade Católica de São Paulo, São Paulo.

SETTON, M.G.J. Perfil social, cultural, expectativas acadêmicas e profissionais dos estudantes da Universidade de São Paulo: uma análise descritiva. 1997. Relatório de Pesquisa entreque à FAPESP, como conclusão ao pós-doutorado - NUPES, Universidade de São Paulo.

SETTON, M.G.J. Narrativas grupais e produtos da mídia: uma relação ambivalente. Cadernos da Pós-Graduação, Campinas, v.3, p.154$162,1999$.

SETTON, M.G.J. A divisão interna do campo universitário: uma tentativa de classificação. Revista Brasileira de Estudos Pedagógicos, Brasília, DF, v. 80, n. 196, p. 451-471, set./dez. 2001.

SETTON, M.G.J. Família, escola e mídia: um campo com novas configurações. Educação e Pesquisa, São Paulo, v. 28, n. 1, p. 107-116, 2002.

SETTON, M.G.J. Rotary Club: habitus, estilo de vida e sociabilidade. São Paulo: AnnaBlume, 2004.

THOMPSON, J.B. Ideologia e cultura moderna. Petrópolis: Vozes, 1995.

WHITAKER, D. Unesp: diferentes perfis de candidatos para diferentes cursos. São Paulo: UNESP, 1989.

ZÉROULOU, Z. La réussite scolaire des enfants d'immigrés: l'apport d'une approche em termes de mobilisation. Revue Française de Sociologie, v. 29, n. 3, p. 447-470, 1988. 
Ficha dos alunos

\begin{tabular}{|c|c|c|c|c|c|c|c|c|c|c|}
\hline Aluno & Idade & Escola & Curso & $\begin{array}{l}\text { Atividade } \\
\text { atual }\end{array}$ & Experiência & $\begin{array}{l}\text { Trabalho } \\
\text { paterno }\end{array}$ & $\begin{array}{c}\text { Instrução } \\
\text { paterna }\end{array}$ & $\begin{array}{l}\text { Trabalho } \\
\text { materno }\end{array}$ & $\begin{array}{c}\text { Instruçãoo } \\
\text { materna }\end{array}$ & $\begin{array}{c}\text { Cursinho } \\
\text { pré-vestibular }\end{array}$ \\
\hline Magy & 38 & $\begin{array}{c}\text { Escola privada/ } \\
\text { freiras. Bolsa do } \\
\text { MEC }\end{array}$ & $\begin{array}{l}\text { Arquite- } \\
\text { tura }\end{array}$ & $\begin{array}{l}\text { Professora: } \\
\text { aulas } \\
\text { particulares }\end{array}$ & Letras - USP & Marceneiro & $4^{a}$ série & $\begin{array}{l}\text { Costu- } \\
\text { reira }\end{array}$ & $4^{\mathrm{a}}$ série & Não \\
\hline Débora & 21 & Escola privada & $\begin{array}{l}\text { Relações } \\
\text { públicas }\end{array}$ & $\begin{array}{l}\text { Estágio/ } \\
\text { Mercedes }\end{array}$ & - & $\begin{array}{c}\text { Torneiro } \\
\text { mecânico } \\
\text { aposentado }\end{array}$ & $\begin{array}{l}\text { Especiali- } \\
\text { zação no } \\
\text { trabalho } \\
\text { 8a série }^{\text {a }}\end{array}$ & Do lar & $4^{a}$ série & $\begin{array}{c}\text { Dois anos } \\
\text { Anglo } \\
1 \text { ano }\end{array}$ \\
\hline Wado & 32 & $\begin{array}{c}\text { Escola } \\
\text { pública/Funda- } \\
\text { çáo Bradesco }\end{array}$ & $\begin{array}{l}\text { Adminis- } \\
\text { tração }\end{array}$ & IPEN-USP & Física & $\begin{array}{l}\text { Pedreiro } \\
\text { operário/ } \\
\text { soldagem }\end{array}$ & $4^{a}$ série & Faxineira & $4^{a}$ série & $\begin{array}{l}\text { Técnico } \\
\text { eletrônica/ } \\
\text { Anglo }\end{array}$ \\
\hline Israel & 35 & $\begin{array}{c}\text { Estadual/ Escola } \\
\text { Técnica de } \\
\text { Contabilidade } \\
\text { Municipal }\end{array}$ & $\begin{array}{l}\text { Adminis- } \\
\text { tração }\end{array}$ & $\begin{array}{c}\text { Assistente } \\
\text { administra- } \\
\text { tivo PRODESP/ } \\
\text { Posto } \\
\text { Poupatempo }\end{array}$ & $\begin{array}{l}\text { PUC - } \\
\text { adminis- } \\
\text { tração: } 1 \\
\text { ano }\end{array}$ & Manobrista & $4^{a}$ série & Faxineira & $4^{\mathrm{a}}$ série & $\begin{array}{c}4 \text { tentativas } \\
\text { dois anos } \\
\text { Anglo }\end{array}$ \\
\hline
\end{tabular}

\begin{tabular}{|c|c|c|c|c|c|c|c|c|c|c|}
\hline Duda & 28 & $\begin{array}{l}\text { Pública/ } \\
\text { Presidente } \\
\text { Prudente }\end{array}$ & $\begin{array}{l}\text { Arqui- } \\
\text { tetura }\end{array}$ & $\begin{array}{l}\text { Arqui- } \\
\text { teto }\end{array}$ & $\begin{array}{l}\text { ECA - } \\
\text { editora- } \\
\text { ção: } 3 \\
\text { anos }\end{array}$ & Mecânico & $4^{\mathrm{a}}$ série & Do lar & $4^{\mathrm{a}}$ série & $\begin{array}{l}\text { Etapa: } \\
1 \text { ano }\end{array}$ \\
\hline Paula & 21 & $\begin{array}{l}\text { Pública/ } \\
\text { Escola } \\
\text { Técnica } \\
\text { Getúlio } \\
\text { Vargas }\end{array}$ & $\begin{array}{l}\text { Arqui- } \\
\text { tetura }\end{array}$ & - & - & Pedreiro & $4^{\mathrm{a}}$ série & $\begin{array}{l}\text { Funcio- } \\
\text { nária } \\
\text { pública } \\
\text { aposenta- } \\
\text { da }\end{array}$ & 4 série & $\begin{array}{c}\text { Cursinho } \\
\text { da POLI/ } \\
1 \text { ano aos } \\
\text { sábados }\end{array}$ \\
\hline Deby & 20 & $\begin{array}{c}\text { Privada/São } \\
\text { Roque }\end{array}$ & Direito & - & - & Tratorista & $8^{a}$ série & Do lar & $\begin{array}{l}\text { Magisté- } \\
\text { rio }\end{array}$ & $\begin{array}{l}\text { Anglo: } 1 \\
\text { ano }\end{array}$ \\
\hline Ricardo & 23 & Escola pública & $\begin{array}{c}\text { Rela- } \\
\text { ções } \\
\text { públicas }\end{array}$ & $\begin{array}{c}\text { Moni- } \\
\text { tor/ cursi- } \\
\text { nho }\end{array}$ & - & Vendedor & $4^{a}$ série & $\begin{array}{c}\text { Faxineira/ } \\
\text { do lar }\end{array}$ & $4^{\mathrm{a}}$ série & $\begin{array}{c}\text { Anglo: } 2 \\
\text { anos }\end{array}$ \\
\hline Wagor & 27 & $\begin{array}{c}\text { Escola } \\
\text { pública/en- } \\
\text { sino técnico }\end{array}$ & $\begin{array}{l}\text { Raio/ } \\
\text { TV }\end{array}$ & $\begin{array}{c}\text { Estágios/ } \\
\text { Rádio USP }\end{array}$ & $\begin{array}{l}\text { UNESP } \\
\text { Rádio e } \\
\text { TV: } 1 \\
\text { ano }\end{array}$ & $\begin{array}{l}\text { Motorista } \\
\text { de ônibus }\end{array}$ & $4^{\mathrm{a}}$ série & $\begin{array}{l}\text { Do lar/ } \\
\text { vende- } \\
\text { dora }\end{array}$ & $\begin{array}{c}\text { Alfabeti- } \\
\text { zação } \\
\text { adulto }\end{array}$ & $\begin{array}{c}\text { Etapa: } 1 \\
\text { ano/ } 4 \\
\text { tentativas }\end{array}$ \\
\hline Breno & 22 & $\begin{array}{c}\text { Publica/par- } \\
\text { ticular } \\
\text { luterana: } \\
\text { bolsa de } \\
\text { estudos }\end{array}$ & $\begin{array}{l}\text { Conta- } \\
\text { bilidade }\end{array}$ & $\begin{array}{c}\text { Caixa } \\
\text { Econômi- } \\
\text { ca: } \\
\text { atendi- } \\
\text { mento ao } \\
\text { público }\end{array}$ & $\begin{array}{l}\text { Técnico } \\
\text { em } \\
\text { eletrônica }\end{array}$ & $\begin{array}{c}\text { Zelador } \\
\text { de escola }\end{array}$ & $4^{\mathrm{a}}$ série & $\begin{array}{l}\text { Inspetora } \\
\text { de alunos }\end{array}$ & $8^{\mathrm{a}}$ série & $\begin{array}{c}\text { POLI e } \\
\text { Etapa: } \\
1 \text { ano }\end{array}$ \\
\hline
\end{tabular}

Educ. Soc., Campinas, vol. 26, n. 90, p. 77-105, Jan./Abr. 2005

Disponível em <http://www.cedes.unicamp.br> 